\title{
GRAIN SCALE STRAINING PROCESSES DURING HIGH TEMPERATURE COMPRESSION OF A PM DISK ALLOY
}

\author{
Wen Tu ${ }^{1}$, Tresa M. Pollock ${ }^{1}$ \\ ${ }^{1}$ University of Michigan; Materials Science and Engineering; 2200 Bonisteel Rd. Ann Arbor, MI 48105, USA \\ Keywords: Disk Alloy, Superplasticity, Strain Mapping, EBSD, Forging.
}

\begin{abstract}
Microstructural-scale straining processes that occur during high temperature compression of powder-consolidated nickel-based superalloy René $88 \mathrm{DT}$ at $1050^{\circ} \mathrm{C}\left(1925^{\circ} \mathrm{F}\right)$ have been studied. A high temperature strain mapping technique has been utilized to quantify grain-level strain accumulation. Orientation imaging has also been employed to study grain-level straining and dislocation storage. Two distinct straining mechanisms were observed. At low strain rates grain boundary sliding dominates while intragranular plastic deformation is observed during high rate compression. Stored strain and microstructural evolution are dependent on strain rate during compression. At low strain rates superplastic deformation occurs with low levels of stored strain and some grain growth. At high strain rates dynamic recrystallization occurs along with higher levels of stored strain within selected grains, particularly those at the high end of the grain size distribution. Dynamic recrystallization results in grain refinement and flow stress softening, which all occur when misorientation within individual grains exceeds a level of approximately $5^{\circ}$.
\end{abstract}

\section{Introduction}

Turbine disks are among the most critical components of aircraft and power generation turbines. The properties of Ni-base disk materials, including strength and fatigue resistance, are sensitive to the grain structure present at the end of a series of deformation processing and heat treatment operations. Grain size control requires a detailed understanding of the operative deformation mechanisms and microstructural evolution during forging. In recent years improvements in operating capability have been achieved via development of alloys that utilize the powder metallurgy $(\mathrm{P} / \mathrm{M})$ processing route [1-4]. Thermomechanical processing of powder alloys requires consolidation, usually by extrusion, and subsequent isothermal forging [5]. Under isothermal forging conditions, the forming process is nominally superplastic, with the advantage of low forging stresses. During isothermal forging the superplastic deformation mode can allow the material to accept large strains without cracking, making forming of large disks with uniform material properties possible [2]. Because of its many advantages, isothermal forging is used in processing of many disk alloys [3].

To date, there have been few fundamental studies on deformation mechanisms and microstructural evolution under conditions relevant to forging. The objective of this research is to quantify strain accumulation and storage processes that occur during high temperature deformation of a $\mathrm{P} / \mathrm{M} \mathrm{Ni}$-superalloy across a range of strain rates and strains under high temperature superplastic and non-superplastic conditions.

\section{Materials and Experiment Procedures}

Experiments were conducted on an as-extruded alloy designated (René88DT) with nominal composition listed in Table 1 [6].

\begin{tabular}{|c|c|c|c|c|c|c|c|c|c|}
\hline \multicolumn{1}{|c|}{ Table I. René88DT alloy composition in wt\% [6]. } \\
\hline Al & $\mathrm{Ti}$ & $\mathrm{Cr}$ & $\mathrm{Co}$ & $\mathrm{Zr}$ & $\mathrm{Nb}$ & $\mathrm{Mo}$ & $\mathrm{W}$ & $\mathrm{C}$ & $\mathrm{Ni}$ \\
\hline 2.1 & 3.7 & 16 & 13 & 0.04 & 0.7 & 4 & 4 & 0.07 & $\mathrm{Bal}$ \\
\hline
\end{tabular}

\section{$\underline{\text { Compression Tests }}$}

Compression samples measuring $5 \times 5 \times 10 \mathrm{~mm}$ were machined by wire EDM. Sample compression surfaces were gridded with $1 \mathrm{~mm}$ groves to insure maximum retention of lubrication to prevent sample from experiencing varying induced strains. Sample faces were ground flat and parallel and one sample face was mechanically polished using the progression of 400-600-800-1200 grit paper followed by 6-1-0.25 micron diamond polishing solution for microstructural observations during compression. Elevated temperature compression tests were conducted with a Instron ${ }^{\circledR} 5582$ system. Specimens were placed between ceramic inserts with boron nitride lubrication applied to contacting surfaces. Specimens were induction heated with an average heating rate of $10^{\circ} \mathrm{C} / \mathrm{sec}$ and air cooled after compression. Testing conditions selected for investigation consisted of: 4 strain rates $(0.00032 / \mathrm{sec}, 0.0032 / \mathrm{sec}, 0.032 / \mathrm{sec}, 0.1 / \mathrm{sec})$, and 4 nominal engineering strain levels $(0.1,0.3,0.5,0.7)$. All experiments were conducted at a temperature of $1050^{\circ} \mathrm{C}\left(1925^{\circ} \mathrm{F}\right)$.

\section{$\underline{\text { Strain Mapping Tests }}$}

A high temperature surface displacement mapping technique developed at University of Michigan has been used to analyze strain accumulation at the grain scale during high temperature deformation. This strain mapping technique, which utilizes physical marker grids on the surface of the sample, analyzes displacement of individual surface markers to measure local accumulated strain. The individual markers are identified by an IDL (Interactive Data Language) program, which uses grayscale to distinguish differences between markers and sample surface in SEM images [7]. Pre and post-deformation SEM images of marker grid are processed through the IDL program to create strain maps of the image area. It has been shown that the surface strains measured using strain mapping are representative of the deformation experienced by the bulk for simple monotonic loading [8]. Using data collected from the strain maps, strain distributions can be correlated with microstructural features. Microstructural scale strain distributions provide information on the uniformity of strain accumulated within the sample, and the role of specific microstructural features.

In the strain mapping procedure, Pt markers are first deposited on a polished surface of a compression sample by sputter coating 
through a 2000 lines/in nickel mesh screen affixed to the surface. $\mathrm{Pt}$ was chosen over other marker materials such as $\mathrm{Au}$ or $\mathrm{Au} / \mathrm{Pd}$ because of its high melting temperature and lower oxidation tendencies at forging temperatures. To ensure sharp contrast of $\mathrm{Pt}$ markers under back-scattered mode in the SEM, the target marker thickness during sputter coating was optimized at $0.5 \mu \mathrm{m}$.

After deposition of the Pt markers and the removal of the nickel mesh, the sample is imaged in a Philips XL30 FEG SEM under back-scattered electron (BSE) mode. Figure 1 shows a typical $\mathrm{Pt}$ gridded sample surface before compression. During sequential straining steps, it is important to be able to return to grid points within the same region, so great care is taken to make sure that the same location of the sample can be identified after compression and the measured displacement of the markers are not skewed by rotation of the sample. After compression testing, the samples are imaged again to measure marker displacements. The pre- and post-deformation SEM images are processed in the IDL code to obtain strain mapping data.

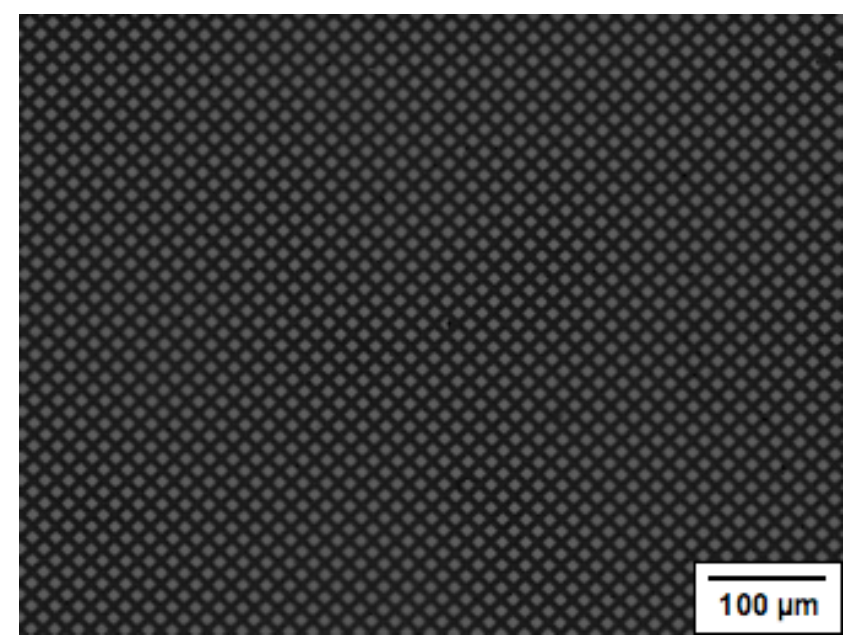

Figure 1. Sample surface gridded with Pt markers before compression.

There are limits to the magnitude of strain that can be mapped using this technique. Marker identification and matching becomes less reliable at accumulated strains beyond 0.1 . Therefore, predeformed samples are used to strain map at 0.3 and 0.5 strain. Samples are compressed to 0.05 below desired strain mapping conditions before marker deposition, compression, and mapping with a "double push" method. Due to marker movement and distortion at high strains, strain mapping cannot map total accumulated strains to 0.3 or 0.5 in an automated fashion, but can be used to manually assess local strains. To assess the role of microstructure over large areas at high strains, the double push method was used.

\section{$\underline{\text { Orientation Imaging }}$}

Grain size and strain storage within René 88DT during compression have been analyzed using orientation imaging (OIM), which uses Electron Backscatter Diffraction (EBSD) to generate diffraction patterns and measure local crystallographic orientation. Abrupt changes in scan point orientation are used to distinguish grain boundaries by setting maximum misorientation between neighboring points within grains, therefore allowing for the measurement of grain size. Changes in crystal orientation that occur due to dislocation storage and local strain gradients can be calculated by measuring misorientation within individual grains [9]. Recent investigations on steel and nickel alloys have demonstrated a correlation between stored dislocation density measured by TEM techniques and grain reference orientation deviation (GROD) maps generated by OIM $[10,11]$.

OIM samples are prepared as follows. Samples are mechanically polished after compression testing with the same procedure as for strain-mapping samples but with an additional vibratory polishing step; after mechanical polishing, the samples are vibratory polished with a Buehler Vibromet 2 in colloidal silica polishing suspension for 3-6 hours at 30-60\% intensity. EBSD scans are taken in a Philips XL30 FEG SEM at $20 \mathrm{kV}$ with a step size of $0.1 \mu \mathrm{m}$. Once scans are complete, a cleaning algorithm removes all scan points with confidence index below 0.15 and minimum grain size was set to 5 scan points.

\section{Experimental Results}

\section{$\underline{\text { Strain Mapping }}$}

Surface strain mapping experiments have been conducted on asextruded René $88 \mathrm{DT}$ at 4 different strain rates $(0.00032,0.0032$, $0.032,0.1 / \mathrm{sec})$ to 3 different engineering strain levels $(0.1,0.3$, 0.5 ). Figure 2 shows a surface strain map of a sample compressed to 0.1 strain at a $0.00032 / \mathrm{sec}$ strain rate. The map illustrates the distribution of Von Mises strain using a color gradient to represent different levels of strain locally. The vertical axis of the map represents the compression direction. The map shows strains in the range of $1.4-0.6$ times the nominal strain, where dark orange and blue areas indicate local areas of high and low strain, respectively.

Closer analysis of sample surface with SEM imaging in the Backscatter Electron (BSE) mode shows highly deformed grains surrounding large non-deforming grains in areas that correlate to strain map areas of high and low strain respectively (Figure 3). These non-deforming grains are observed in samples compressed at all strain rates. Large grains are present in René88DT before compression, which leads to the conclusion that the nondeforming large grains are a product of the powder extrusion process and not of the compression testing. Furthermore, electron probe micro-analysis (EPMA) indicates that there were no statistically significant compositional differences in the major elements in the large grains compared to the nominal René88DT composition. In this case the strain mapping technique is clearly useful for identification of microstructural features that are significant to the deformation process.

In Figure 3 and 4, it is noteworthy that individual grains become visible on the polished surfaces after compression due to the development of large offsets at grain boundaries that occur in samples compressed at the lower two strain rates. These offsets were not observed in samples compressed at the higher two strain rates. It has been shown that during superplastic deformation, grains may reorient by as much as 15 degrees to accommodate the strain, and this is accompanied by the development of large offsets between grains at the sample surface [12]. Therefore, the transition between low strain rate conditions where the grain offsets develop and high strain rates where they are absent indicates a change in straining mechanism (Figure 4). 
Figure 5 shows the distribution of strain within samples compressed at $0.00032 / \mathrm{sec}$ strain rate. The distributions indicate that straining occurs very inhomogeneously on the micron scale (considering the $12.7 \mu \mathrm{m}$ spacing between center of neighboring markers). Figure 5 illustrates that the majority of strain is in the region of $0.8-1.2$ times the nominal strain, though localized strain can range from 0.6 to 1.4 times the macroscopically imposed stress, as stated above. The full-width half-max (FWHM) of the Von Mises strain distributions are shown in Figure 6. The distribution width, i.e., the variability in the local strains, changes as a function of strain and strain rate, though the reasons for the changes are not yet fully understood.

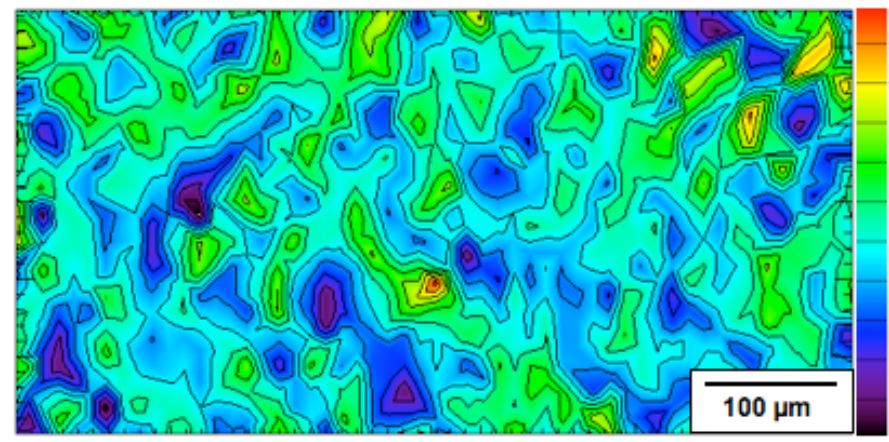

21.5

20.6

19.7

18.8

17.8

16.9

15.9

15.1

14.1

13.2

Figure 2. Von Mises strain map for sample compressed at $0.00032 / \mathrm{sec}$ to $14.5 \%$ strain. Scale bar in percent Von Mises strain.

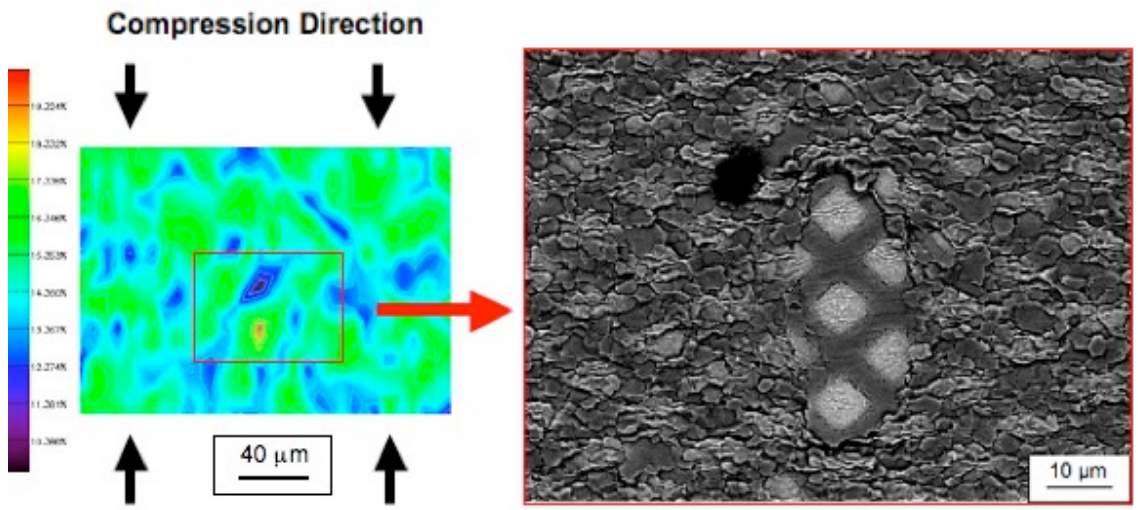

Figure 3. BSE SEM image of large non-deforming grain surrounded by highly deformed grains after compression on right compared to strain map of area around large grain. Compression at $0.001 / \mathrm{sec}$ strain rate to 0.228 engineering strain.
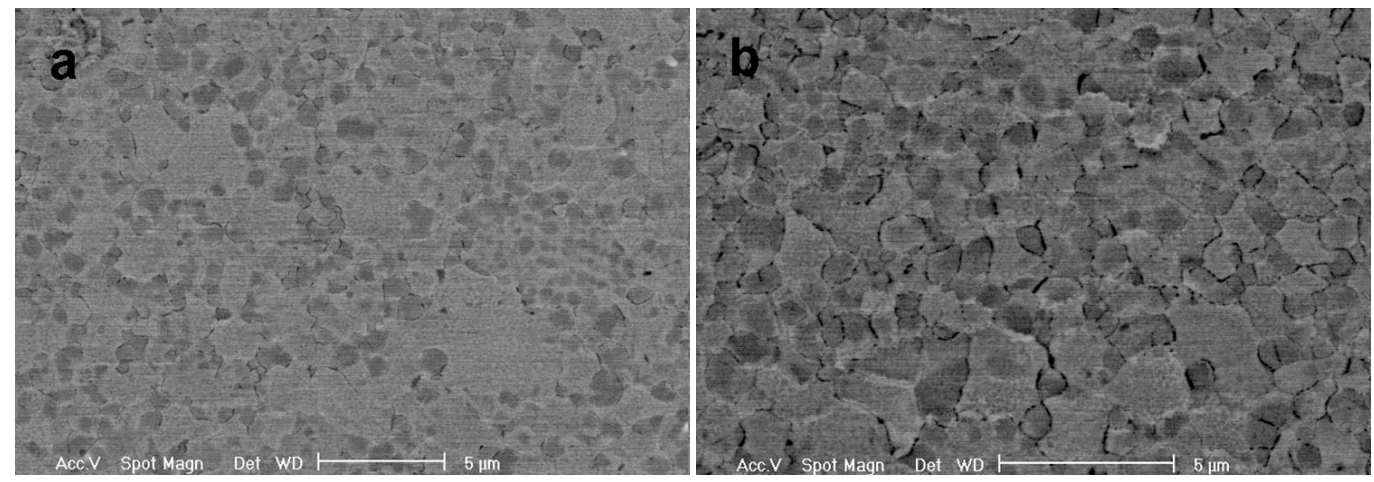

Figure 4. Microstructure of strained René88DT shows grain boundary offsets for superplastic deformation. (a) 0.05 strain, $0.032 /$ sec. (b) 0.05 strain, $0.0032 / \mathrm{sec}$. 


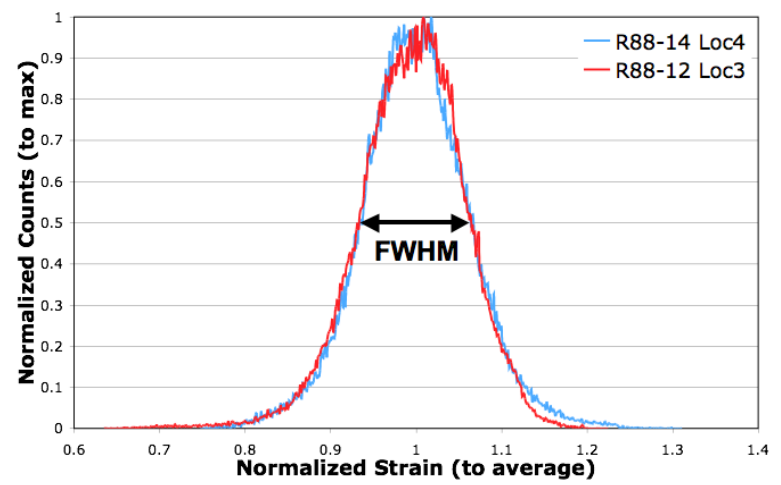

Figure 5. Von Mises strain distribution for 0.1 strain at $0.00032 / \mathrm{sec}$ strain rate. Different colors indicate different samples. Black line with areos indicates where FWHM is measured.

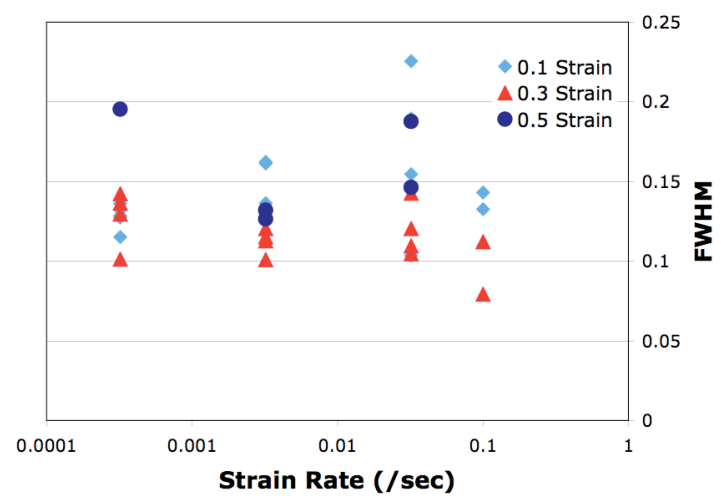

Figure 6. Full-width half-max of strain distributions for all René88DT strain maps. Y-axis is width of normalized strain distribution, such as shown in Figure 5. Strain rates are displayed in $\sec ^{-1}$.

\section{Orientation Imaging}

OIM Scans were taken of samples after compression with the test conditions summarized above to examine the evolution of the grain structure. With OIM inverse pole figures, Figure 7 shows the grain size following compression as a function of strain rate and strain. The different colors correlate to different orientation of the scan points. Black borders are drawn at the grain boundaries as determined by the TSL OIM analysis software [9]. As shown in Figure 7 , there is no texture present after compression for engineering strains up to 0.7 .

\section{$\underline{\text { OIM Grain Size Analysis }}$}

From Figure 7 it is evident that there is significant evolution of the grain structure during compression over the range of conditions investigated and:

- Strain rate during compression affects the final average grain size producing finer grains as strain rates increase from $0.00032 / \mathrm{sec}$ to $0.1 / \mathrm{sec}$.

- There is substantial grain growth during compression at a rate of 0.00032 and $0.0032 / \mathrm{sec}$ while no normal grain growth is evident at the higher two strain rates.

- Grain refinement by recrystallization occurs almost immediately upon compression at the higher two strain rates while it occurs much later at the lower two strain rates.
Figure 8 is a plot of average ASTM grain size of all the samples in the testing matrix as a function of strain rate at varying engineering strains. At all strains, there is a substantial decrease in ASTM grain size as strain rate during compression increases. This behavior is most apparent at the highest strain level (0.7) where the grain size difference between the slowest $(0.00032 / \mathrm{sec})$ and highest $(0.1 / \mathrm{sec})$ strain rates is almost 2.5 ASTM numbers. This type of grain refinement occurs by dynamic recrystallization.

Figures 9-12 illustrates the progression of grain size superimposed on the true stress-strain curves of samples compressed to 0.7 engineering strain. In general, flow softening was observed over the range of conditions investigated, which was associated with grain growth and dynamic recrystallization. At the slowest compression rate $(0.00032 / \mathrm{sec})$, as seen in Figure 9, the grains grow almost immediately during compression. At $\sim 20 \%$ compression, grains experience dynamic recrystallization followed by another round of grain growth. Growth continues to a critical size around 0.6 true strain where recrystallization initiates again. Figure 10 shows the grain size progression for compression at $0.0032 / \mathrm{sec}$, where behavior is comparable to that of samples at $0.00032 / \mathrm{sec}$; the grains experience initial growth followed by grain refinement after some critical strain and grain size. Figures 11 and 12 plot the true stress-strain curves of samples compressed at 0.032 and $0.1 / \mathrm{sec}$ strain rates, respectively. The evolution of the grain size during compression is similar at these two strain rates, 
but distinctly different from the evolution at the slower two strain rates. Recrystallization occurs early with a continuing trend of smaller grain size compared to as-extruded grain size.

Plotting stress as a function of strain rate at 0.5 true strain on a logarithmic scale gives a strain rate sensitivity coefficient $(m)$ of 0.69 for strain rates under $0.032 / \mathrm{sec}$, which is within the range of $m$ associated with superplastic behavior [12]. The magnitude of the rate sensitivity coefficient $(m)$ decreases to as low as $m=$ 0.204 for strain rates at $0.032 / \mathrm{sec}$ and above, indicating that deformation mechanism changes for those strain rates. Lower rate sensitivies are typically taken as a evidence for transition to power law creep. It is important to note that though flow stress softening occur at all strain rates, adiabatic heating may be a cause of softening at the higher two strain rates where the change in temperature during compression may be significant.
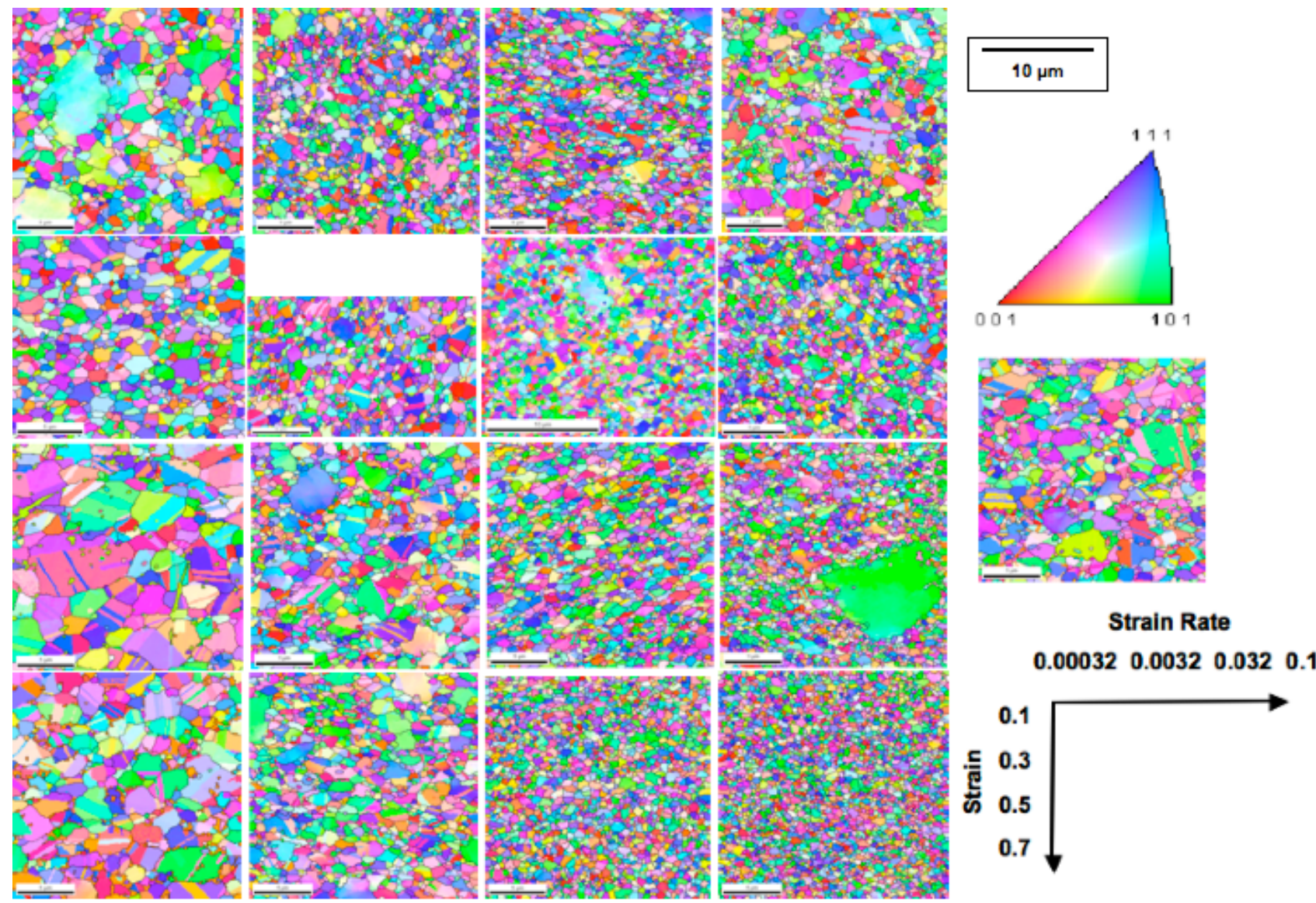

Figure 7. René88DT OIM IPF Map after compression. As-extruded sample is on the far right. Strain rates are in $\sec ^{-1}$. 


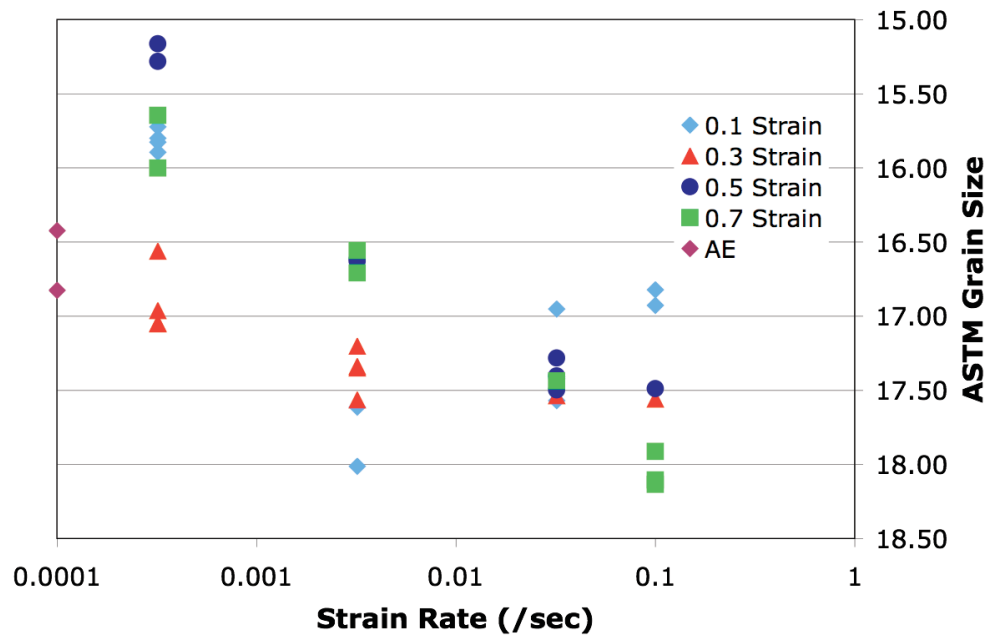

Figure 8. René88DT ASTM grain size vs. strain rate at 4 strain levels. As-extruded (AE) grain size also included.

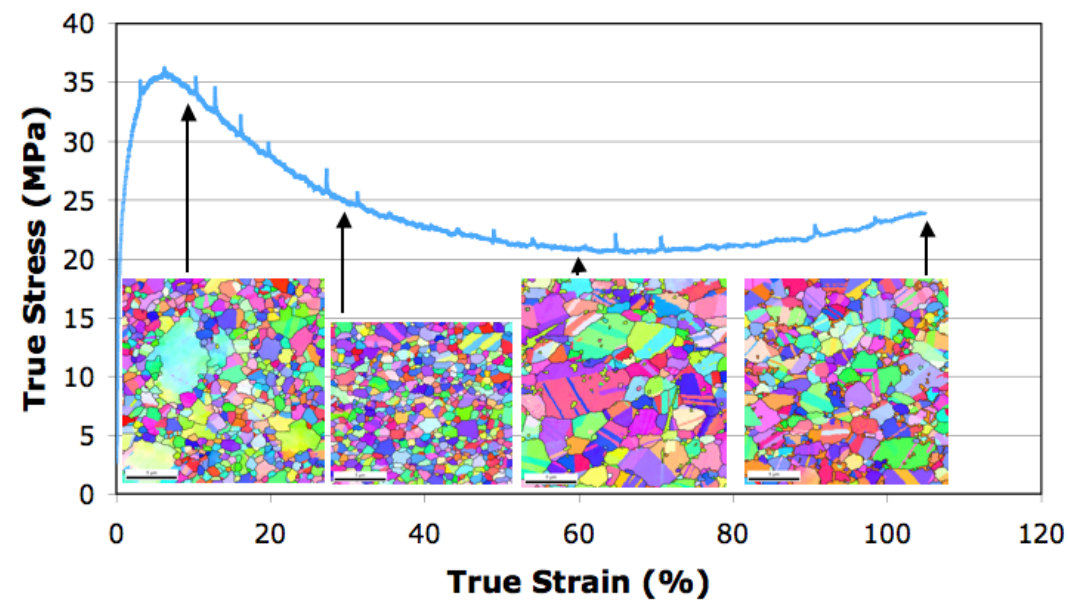

Figure 9. René88DT $0.00032 / \mathrm{sec}$ true stress-strain curve with superimposed IPF illustrating grain size evolution.

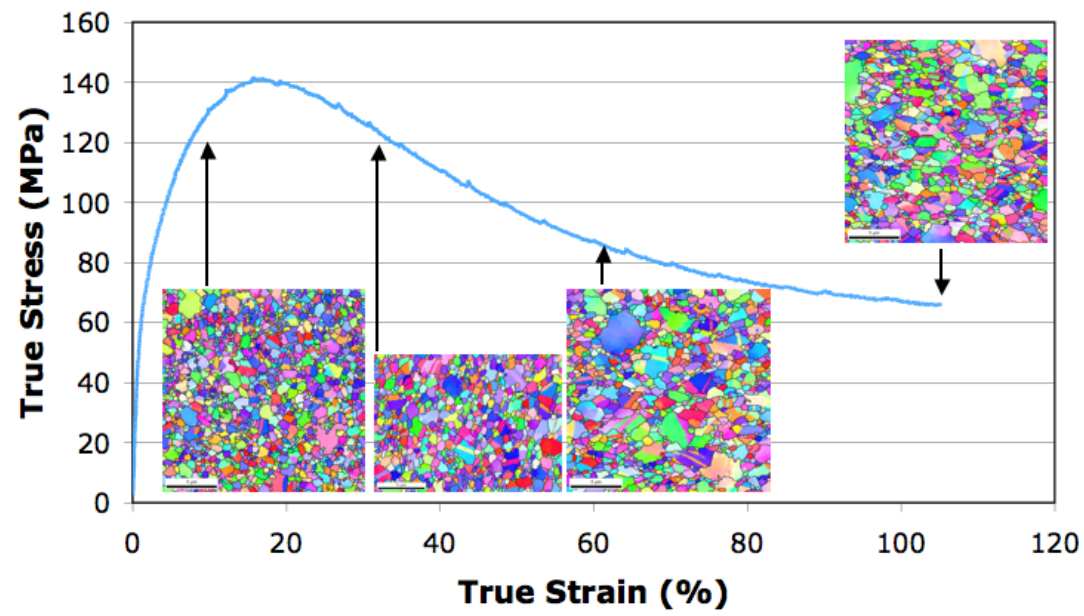

Figure 10. René88DT $0.0032 / \mathrm{sec}$ true stress-strain curve with superimposed IPF illustrating grain size evolution. 


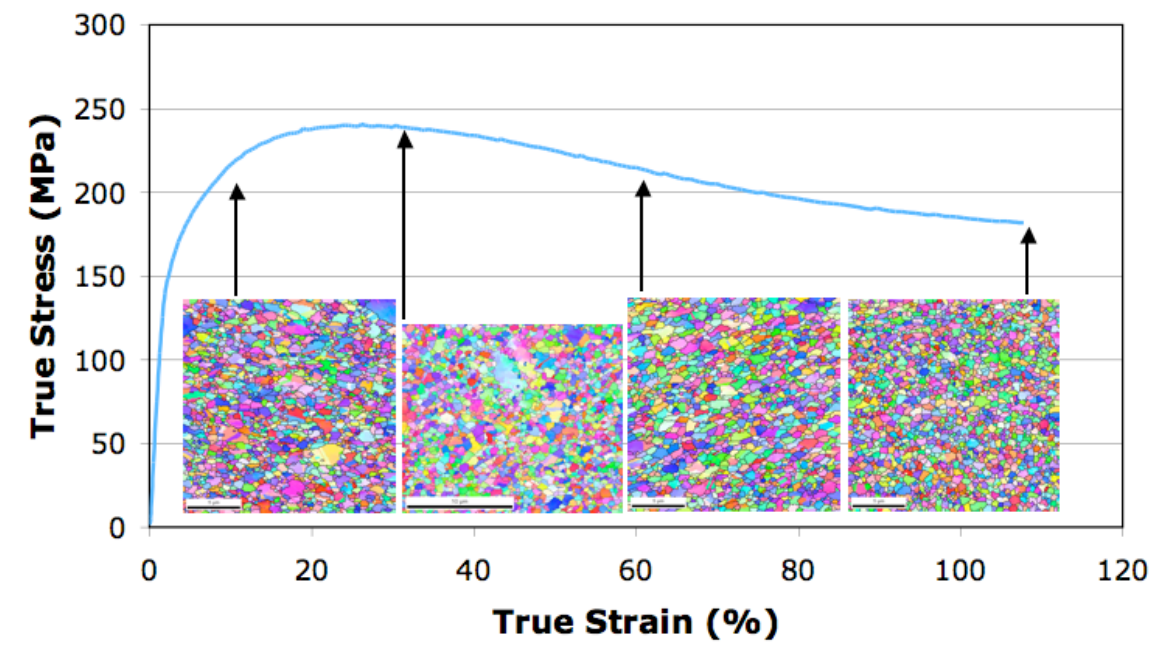

Figure 11. René88DT $0.032 / \mathrm{sec}$ true stress-strain curve with superimposed IPF illustrating grain size evolution.

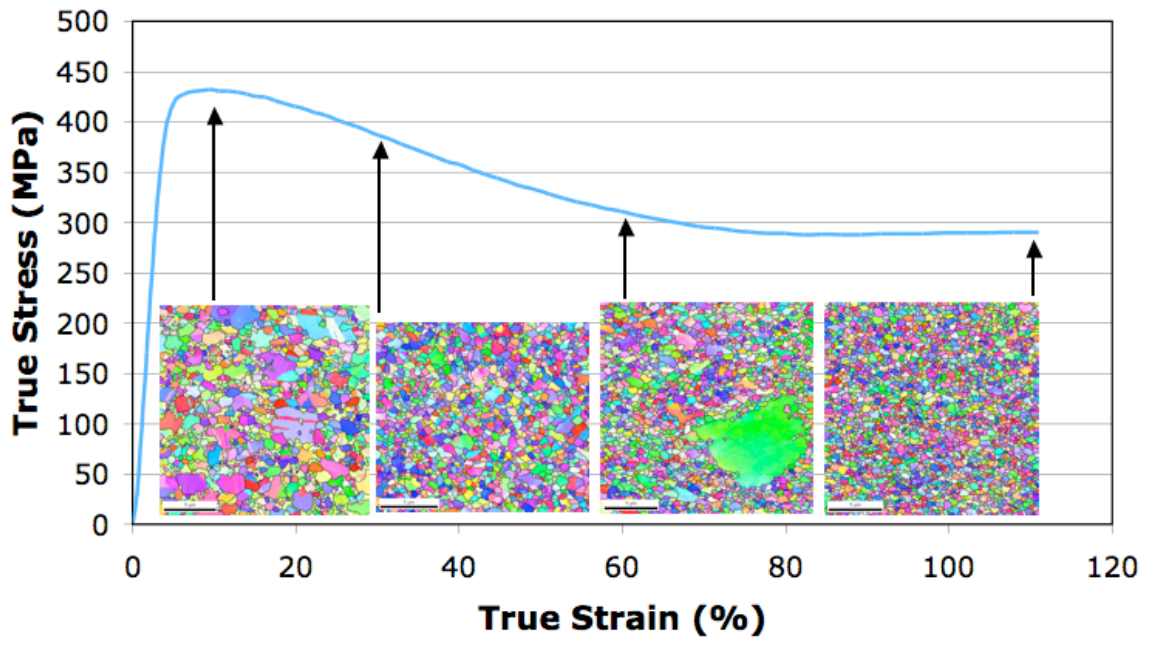

Figure 12. René88DT 0.1/sec true stress-strain curve with superimposed IPF illustrating grain size evolution.

\section{$\underline{\text { OIM Misorientation Analysis }}$}

Figure 13 shows the OIM GROD maps across the range of strain and strain rate conditions investigated at $1050^{\circ} \mathrm{C}\left(1925^{\circ} \mathrm{F}\right)$. These data demonstrate that at every compression strain level, misorientation increases with strain rate. This is summarized in Figure 14, where area fraction with GROD above 0.7 degrees as a function of strain rate at 4 strain levels is shown. It can also be observed from Figures 13 and 14 that the GROD fraction at the slowest strain rate $(0.00032 / \mathrm{sec})$ continues to decrease after the initial small increase from the as-extruded state. This result indicates that there is very little misorientation accumulated within the grains during compression. Furthermore, the misorientation that is initially present is recovered with straining. At the next higher strain rate, a similar trend occurs where the GROD fraction decreases at the highest strain.

At the highest two strain rates, the GROD fraction stays relatively constant with a gradual and small decrease at higher strains. Recrystallization clearly occurs at these two strain rates and the GROD analysis clearly shows retained strains at all stages of compression. 

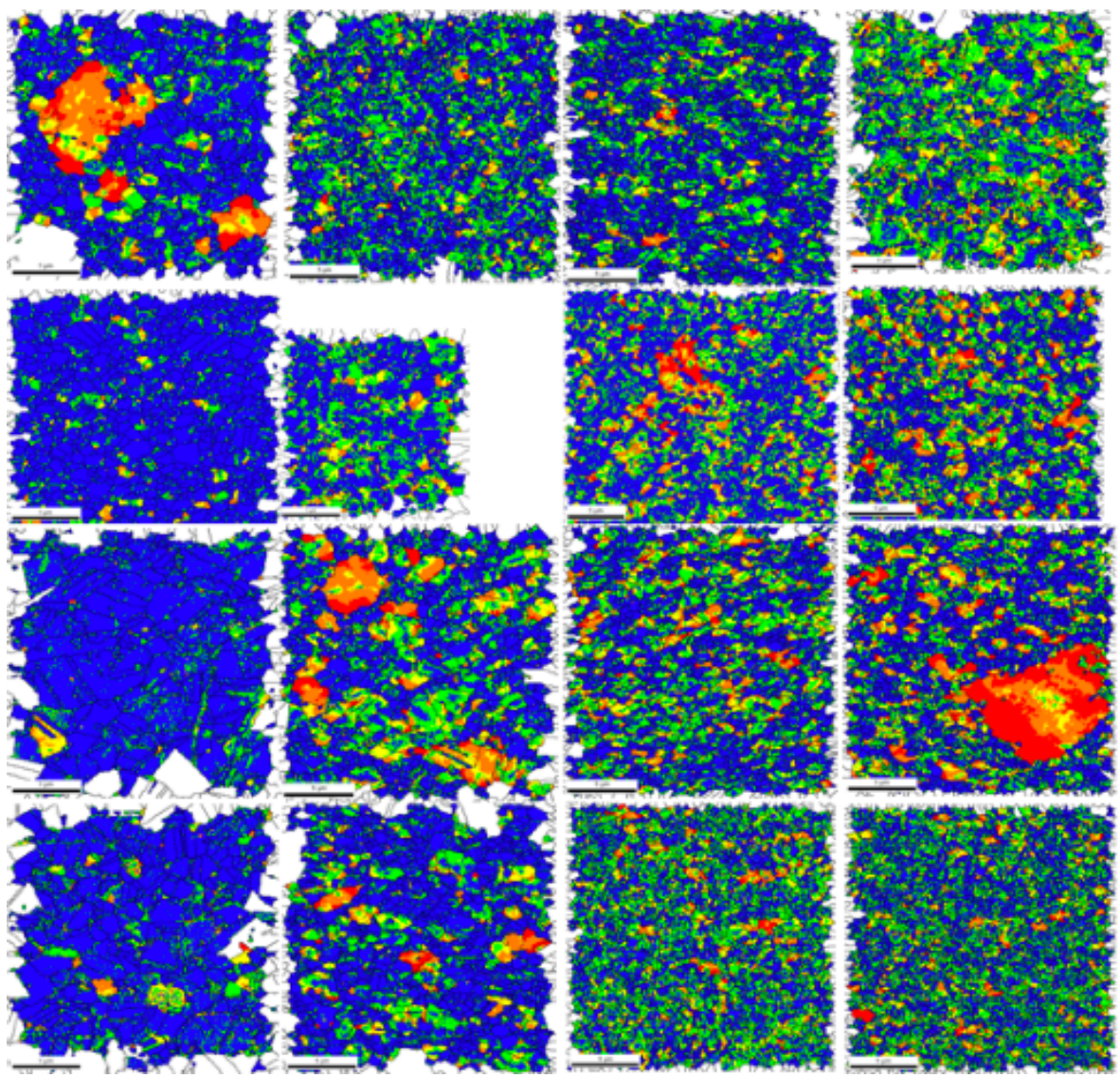

Figure 13. René $88 \mathrm{DT} 1050^{\circ} \mathrm{C}\left(1925^{\circ} \mathrm{F}\right)$ GROD map matrix after compression. As-extruded sample GROD Map is included on far right. All images at same magnification.

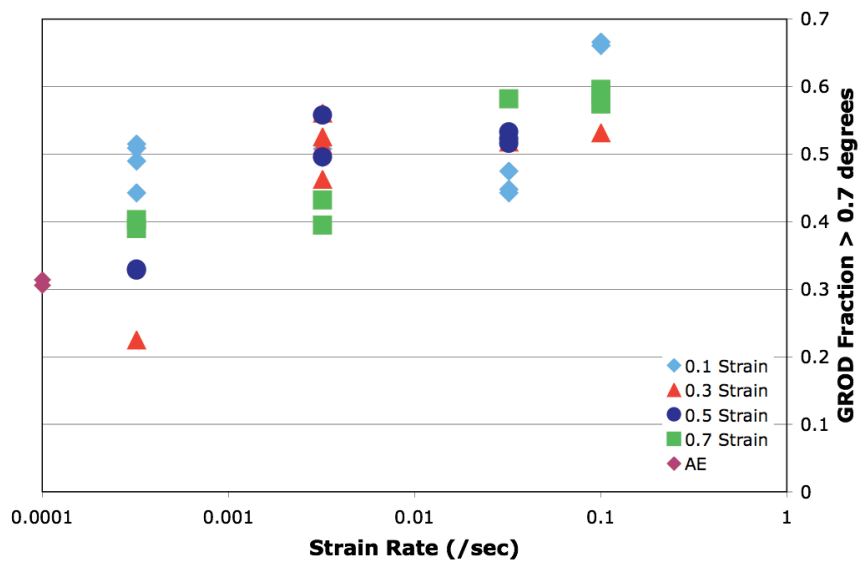

Figure 14. René 88DT point fraction with GROD above 0.7 degrees as a function of strain rate at $1050^{\circ} \mathrm{C}\left(1925^{\circ} \mathrm{F}\right)$.

\section{Discussion}

While control of grain size is important for optimization of turbine disk properties, there are many phenomena during forging and in subsequent heat treatment that influence grain size that are incompletely understood. Though compression conditions during forging (strain, strain rate, temperature) clearly influence final grain size, the mechanistic details have not been well understood due to a lack of understanding of the microstructural-scale straining processes. In this study, a combination of strain mapping and OIM GROD analysis serves to provide novel and in-depth analysis of microstructural deformation and strain storage at the grain scale. Strain mapping data has provided quantitative information on strain distribution at the microstructural scale with images that clearly illustrate the non-uniformity of strain accumulation. Strain maps were also useful in distinguishing highly straining grains from non-deformable grains within the René 88DT microstructure. OIM GROD maps permit evaluation 
of the stored dislocation density within the microstructure on a much larger scale than that of transmission electron microscopy (TEM) analysis by measuring degrees of misorientation across individual grains and correlating it to stored dislocation density by using the equation $\rho=(\theta / b)^{2}$ where $\rho$ is the dislocation density, $\theta$ is the misorientation in radians, and $b$ is the Burger's vector $(0.254 \mathrm{~nm}$ for René $88 \mathrm{DT})$. Dislocation densities can then be utilized as in put for a recrystallization model [13]. From the GROD analysis, it appears that there is a critical level of misorientation (dislocation density) that can accumulate within individual grains before the onset of recrystallization is triggered. This maximum misorientation seems to vary as a function of strain rate. Though it has been reported that dynamic recrystallization can start in alloys at nominal strain of as low as 0.1 [4], it has previously not been possible to quantify strain that accumulates within individual grains before dynamic recrystallization on a large scale.

Due to the observed surface grain boundary offset of samples at low strain rates, the measured strain rate sensitivity coefficient $(m)$ of 0.69 at low strain rates, and the change in GROD accumulation between low strain rate and high strain rate over the range of conditions investigated, it is clear that superplastic deformation with extensive grain boundary sliding occurs at lower strain rates with a transition to innergranular deformation and dynamic recrystallization at higher strain rates. Furthermore, grain growth observed during low strain rate compression is comparable to enhanced grain growth seen during superplastic deformation in IN-100 [14, 15]. Increasing dislocation density at higher strain rates, as seen in GROD maps, combined with decreasing grain size, clearly show the occurrence of dynamic recrystallization resulting in grain refinement. Stress strain curves overlaid with OIM IPF scans showed that softening and grain refinement occurs at a strain of 0.1 , which is comparable to onset of recrystallization at 0.05 strain seen in $\mathrm{IN}-100$ at $1038^{\circ} \mathrm{C}\left(1900^{\circ} \mathrm{F}\right)$ [14].

\section{Conclusions}

From microstructural analysis, strain mapping, and OIM analysis of René 88DT over the range of conditions investigated:

- $\quad$ Strain mapping and OIM analysis show that straining occurs inhomogeneously at the grain-size scale, with plastic strains varying by a factor of 0.4 on a grain-to-grain basis.

- There is a transition in strain accumulation and storage mechanisms as strain rate increases from $0.0032 / \mathrm{sec}$ to $0.032 / \mathrm{sec}$

- Superplastic deformation occurs at the lowest strain rates. Superplasticity enhanced grain growth occurs at low strain rates, yielding larger final grain size compared to the asextruded material.

- Deformation by power law creep mechanisms occurs at high strain rates. Dynamic recrystallization was triggered when local strains exceeded a critical value.

- Dynamic recrystallization initiates at relatively low nominal strains (0.1).

\section{Aknowledgements}

The authors acknowledge useful discussions with Mr. Eric Payton, and Professors Mike Mills and Yunzhi Wang of the Ohio State University and Deborah Whitis, Dave Mourer, and Dan Wei of GE Aviations. The authors are grateful for the support of GE Aviation via the GE-USA program.

\section{References}

1. S.T. Wlodek, M. Kelly and D.A. Alden, "The Structure of Rene 88DT", Superalloys 1996, (1996), 129-136

2. H. Fecht, and D. Furrer, "Processing of nickel-base superalloys for turbine engine disc applications", Advanced Engineering Materials, 2(12) (2000), 777787.

3. C.P.J. Blankenship et al., "Hot-Die Forging of P/M NiBased Superalloys", Superalloys 1996, (1996), 653-662.

4. D.D. Whitis, "Recovery and Recrystallization After Critical Strain in the Nickel-Based Superalloy Rene 88DT," Superalloys 2004, (2004), 391-400.

5. J. Moll and BJ. McTiernan, "Powder Metallurgy Superalloys", (www.asminternational.org. 2002, ASM International).

6. D.D. Krueger, R.D. Kissinger, and R.G. Menzies, "Development and Introduction of a Damage Tolerant High Temperature Nickel-Based Alloy, René 88DT", Superalloys 1992, (1992) 277-286.

7. N. Biery, M. De Graef, and T.M. Pollock, "A method for measuring microstructural-scale strains using a scanning electron microscope: Applications to gammatitanium aluminides", Metallurgical and Materials Transactions a-Physical Metallurgy and Materials Science, 34A(10) (2003), 2301-2313.

8. A. Wu, "Local Strain Development in High Temperature Rual Intermetallic Alloys, in Materials Science and Eningeering", (Ph.D thesis, University of Michigan: Ann Arbor, MI, 2006).

9. A.J. Schwartz, M. Kumar, and B.L. Adams, Electron Backscatter Diffraction and Future Directions (Kluwer Academic/Plenum Publishers, 2000).

10. M. Kamaya, A.J. Wilkinson, and J.M. Titchmarsh, "Measurement of plastic strain of polycrystalline material by electron backscatter diffraction", Nuclear Engineering and Design, 235(6) (2005), 713-725.

11. M. Kamaya, A.J. Wilkinson, and J.M. Titchmarsh, "Quantification of plastic strain of stainless steel and nickel alloy by electron backscatter diffraction", Acta Materialia, 54(2) (2006), 539-548.

12. J.W.Edington, K.N. Melton, and C.P. Cutler, "Superplasticity", Progress in Materials Science, 21(2) (1976) 63-170.

13. D. Raabe and L. Hantcherli, "2D cellular automaton simulation of the recrystallization texture of an IF sheet steel under consideration of Zener pinning", Computational Materials Science, 34(4) (2005) 299 313.

14. R.G.Menzies, G.J. Davies, and J.W. Edington, "Microstructural Changes During Superplastic Deformation of Powder-Consolidated Nickel-Based Super-alloy IN-100", Metal Science, 16(10) (1982), 483-494.

15. R.G. Menzies, J.W. Edington, and G.J. Davies, "Superplastic Behavior of Powder-Consolidated NickelBased Super-alloy IN-100", Metal Science, 15(5) (1981), 210-216. 